\title{
Influence of Extraction Solvent on Antioxidant Properties of Guiera senegalensis J.F. Gmel (Combretaceae) Leaves
}

\author{
${ }^{1}$ S.S. Kankara and ${ }^{2}$ R. Go \\ 1Department of Biology, Faculty of Natural and Applied Sciences, Umaru Musa Yar'adua University, Katsina, Katsina State, Nigeria \\ ${ }^{2}$ Department of Biology, Faculty of Science, Universiti Putra Malaysia, 43400 Serdang, Selangor Darul Ehsan, Malaysia \\ [Corresponding Author: E-mail: sulaiman.kankara@umyu.edu.ng]
}

\section{ABSTRACT}

Guiera senegalensis is widely used in West Africa for traditional medicine. In Northern Nigeria, it is used for general well-being by women during postpartum recovery period. In this study, we report the effect of extraction solvents viz acetone, chloroform, ethanol, methanol (each at $50 \%$ and $75 \%$ concentrations) and water on the phenolic antioxidant and antioxidant activity of it's leaves. Total Phenolic Content (TPC) and Total Flavonoid Content (TFC) assays were used to determine the phenolic antioxidants. Antioxidant activity was evaluated by measuring scavenging effect on 2,2'- diphenyl-1-picrylhydrazyl (DPPH) radical, Ferric Reducing Antioxidant Power (FRAP) and Total Antioxidant Capacity (TAC) using phosphomolybdate assay. Results shows that extraction solvents significantly $(P<0.05)$ affect phenolic antioxidants extraction and antioxidant properties. Highest TPC value $(109.20 \pm 3.99 \mathrm{mg}$ GAE/100g DW) was obtained in $75 \%$ ethanol. $75 \%$ acetone showed the highest TFC value $(414.60 \pm 7.60 \mathrm{mg}$ QE $/ 100 \mathrm{~g} \mathrm{DW})$. Highest DPPH radical scavenging activity $(95.82 \pm 0.63 \%)$ was observed in water solvent. $50 \%$ chloroform showed the best FRAP value $(282.73 \pm 29.80 \mathrm{mg} A A E / 100 \mathrm{~g} D W)$. While $75 \%$ methanol showed the highest TAC value (102.44 $\pm 3.44 \mathrm{mg} \mathrm{AAE} / 1 \mathrm{~g} \mathrm{DW}$ ). Based on its highest TFC value as well as its insignificant differences with other solvents that showed higher values for TPC, FRAP and TAC, 75\% acetone appeared to be the solvent for extracting phenolic antioxidants. Correlations study indicates highly significant positive ( $p<$ 0.001 ) linear correlations between phenolic antioxidants and antioxidant activities. The highest correlation $\left(r^{2}=0.845\right)$ was observed between TFC and TAC followed by TFC and DPPH $\left(r^{2}=0.733\right)$. Another significant correlation $\left(r^{2}=0.659\right)$ was also observed between TFC and FRAP. Further studies aimed at isolating and identifying specific compounds responsible for antioxidant activity in $G$. senegalensis are recommended.

Keywords: Antioxidant activity, extraction solvents, Guiera senegalensis and phenolic antioxidants.

\section{INTRODUCTION}

Free radicals are highly reactive chemicals produced naturally in the body and play a significant role in many normal cellular processes (Brewer, 2011). These free radicals, however, when present in high concentration are hazardous to the body because they damage major cellular components such as DNA, proteins and cell membrane (Koltover, 2010). To overcome the destructive effects of free radicals, the body produces endogenous antioxidants that interact with and neutralize the free radicals (Shalaby and Shanab, 2013). The endogenous antioxidants are, however, not sufficient to counteract all the free radicals, as such, the body requires external (exogenous) antioxidants. Exogenous antioxidants can be natural (sourced from herbs, fruits and/or vegetables) or manmade (Brewer, 2011).

Natural antioxidants from plants sources are gaining more popularity because they are considered safer than their synthetic counterparts such as butylated hydroxy- anisol (BHA) and butylated hydroxyl toluene (BHT) (lqbal et al. 2014). This is because indications have shown that synthetic antioxidants are associated with side effects and are believed to cause significant damage to the lungs, liver and kidneys (Shalaby and Shanab, 2013). Repeated studies have shown that $\mathrm{BHA}$ and $\mathrm{BHT}$ are involved in 
carcinogenesis, liver enlargement, hampered DNA synthesis and consequently retarded cell development (Koltover, 2010).

Natural antioxidants such as polyphenolic compounds are obtained from plant materials via extraction. However, because of the diverse chemical nature of phenolic compounds, they are selectively soluble in different solvents. Hence no single solvent is considered standard for extracting phenolic compounds (Boeing et al., 2014). Optimizing extraction solvent is therefore a crucial step in the extraction of phenolic antioxidants.

Guiera senegalensis J.F. Gmel (Combretaceae), locally known as "sabara" or "barbarta" in hausa language of Northern Nigeria is widely distributed in western Africa (Sombie et al., 2011). Traditionally, G. senegalensis is used to treat various illnesses such as hypertension, malaria, cough, diabetes and many microbial infections (Fiot et al., 2006). The plant is also widely used by women in Katsina State, Nigeria during postpartum period for enhancing general wellbeing. Many researchers have reported various medicinal properties of $G$. senegalensis including antimicrobial (Kudi et al., 1999 and Fiot et al., 2006), antiulcer (Aniagu et al., 2005), antimalarial (Benoit et al., 1996, Ancolio et al., 2002) and antiviral activities (Lamien et al., 2005), to mention but few. Although some researchers reported antioxidant properties of $G$. senegalensis (Mariod et al., 2006; Sombie et al., 2011; Abubakr et al., 2013), to the best of our knowledge no study is reported on the optimization of protocol for the extraction of natural antioxidants from this plant. It is against this background that this study was designed to determine the best solvent for extraction of phenolic antioxidants from this medicinally important plant.

\section{MATERIALS AND METHODS}

\section{Plant material}

Guiera senegalensis leaves were collected from Umaru Musa Yar'adua University Campus
Katsina, Katsina State, Nigeria. The plant was authenticated by Professor Munier Abd el Ghani of the Department of Biology, Umaru Musa Yar'adua University, Katsina and a voucher specimen was deposited in the Herbarium of the same Department with voucher specimen number SSK009.

\section{Drying and grinding of plant material}

$G$. senegalensis leaves were evenly spread on a tray and kept in the laboratory at a temperature of approximately $36^{\circ} \mathrm{C}$ until completely dry for 5 days. The dried leaves were ground using a mill (Retsch, SM100 comfort Hann, Germany). The powder obtained was packaged in nylon linear low density polyethylene pouches and stored in dark at an ambient temperature until used.

\section{Extraction of plant material}

Two grams (2g) G. senegalensis leaves powder was put in $50 \mathrm{ml}$ conical flask covered with parafilm (Pechiney plastic packaging Menasha, Wisconsin U.S.A) and wrapped with aluminium foil (Diamond Reynolds, Richmond, U.S.A.) and extracted with $20 \mathrm{ml}$ ethanol, methanol, acetone, chloroform (each at $25 \%, 50 \%, 75 \%$ and $100 \%$ concentrations) or deionized water in a temperature- controlled water bath shaker (WNB 7- 45, Memmert, Germany) at a constant speed for 120 minutes. Crude extracts were then filtered through Whatmann No. 1 filter paper (Whatmann International Ltd, England). Filtrates were collected in amber bottles and used directly for the estimation of phenolic antioxidant and evaluation of antioxidant activities using various biochemical assays (Thoo et al., 2010).

\section{Determination of Total Phenolic Content (TPC)}

Total Phenolic Content (TPC) was determined using Folin-Ciocalteu's $(\mathrm{FC})$ method as reported by Thoo et al. (2010) with slight modifications. Measurements were calibrated to a standard curve of prepared gallic acid solution (10 $100 \mu \mathrm{g} / \mathrm{ml})$ with equation $\mathrm{y}=0.01 \mathrm{x}-0.009\left(R^{2}=\right.$ 0.999) and TPC was then expressed as milligram 
of gallic acid equivalent (GAE) per 100g of dry weight (DW).

\section{Determination of Total Flavonoid Content (TFC)}

Total Flavonoid Content (TFC) was determined using aluminium chloride calorimetric assay reported by Kaur and Mondal (2014) with slight modifications. Measurements were calibrated to a standard curve of prepared quercetin solution $(0-800 \mu \mathrm{g} / \mathrm{ml})$ with equation $\mathrm{y}=0.0000 \mathrm{x}+0.003$ $\left(R^{2}=0.981\right)$ and TFC was then expressed as milligram quercetin equivalent (QE) per $1 \mathrm{~g}$ dry weight (DW).

\section{Evaluation of antioxidant activity \\ 2,2'- diphenyl-1- picrylhydrazyl (DPPH) radical scavenging activity}

Antioxidant capacity through DPPH scavenging activity was determined according to the protocol reported by Tan et al., 2013 with slight modifications. Percentage DPPH scavenging activity was determined using the relation:

DPPH scavenging activity $(\%)=\left[\left(A_{0}-A_{30}\right) / A_{0}\right]$ * 100

Where $A_{0}=$ Absorbance at time $0 ; A_{30}=$ Absorbance after 30 minutes.

\section{Ferric reducing antioxidant power (FRAP)}

The FRAP assay was carried out using the protocols of Benzie and Strain (1996) as reported by Thaipong et al., (2006). Measurements were calibrated to a linear standard curve of prepared ascorbic acid solution $(5-35 \mathrm{mg} / \mathrm{ml})$ with equation $y=0,045 x+0.395\left(R^{2}=0.996\right)$ and results expressed as milligram ascorbic acid equivalent (AAE) per $100 \mathrm{~g}$ dry weight (DW).

\section{Total Antioxidant Capacity (TAC)}

Total antioxidant capacity was determined using phosphomolybdate assay described by Mohammed et al. (2014) with slight modifications. Measurements were calibrated to a linear standard curve of prepared ascorbic acid solution $(100-700 \mu \mathrm{g} / \mathrm{ml})$ with equation $\mathrm{y}=$ $0.0016+0.0222\left(R^{2}=0.999\right)$ and results expressed as milligram ascorbic acid equivalent (AAE) per $1 \mathrm{~g}$ dry weight (DW).

\section{Statistical analysis}

Results were expressed as mean \pm standard deviation of replicate extraction and triplicate of assays and analysed using SPSS software (version 20). One- way analysis of variance (ANOVA) with Duncan's test was carried out to test significant difference between levels of treatments. A P value of $<0.05$ was considered an indication of statistically significant difference. Pearson correlations between variables were also established.

\section{RESULTS AND DISCUSSION}

Total Phenolic Content (TPC)

Effect of extraction solvent on total phenolic content (TPC) in G.senegalensis is presented in Figure 1. From the figure, it can be seen that extraction solvent significantly $(p<0.05)$ affects TPC in G.senegalensis. The TPC obtained ranged from $34.35 \mathrm{mg} G A E / 100 \mathrm{~g}$ DW to $109.20 \mathrm{mg}$ GAE $/ 100 \mathrm{~g}$ DW. $75 \%$ ethanol produced the highest TPC (109.20mg GAE/100g DW) followed by $75 \%$ acetone $(107.16 \mathrm{mg}$ GAE/100g DW) while the least TPC $(34.35 \mathrm{mg}$ GAE $/ 100 \mathrm{~g}$ DW) was observed in $75 \%$ chloroform. No significant $(p<0.05)$ difference observed between TPC produced by $75 \%$ ethanol and $75 \%$ acetone. This shows that phenolic compounds in this plant are best extracted using aqueous solvents compared to mono solvent system. Fatiha et al., (2012) also report that 50\% ethanol produced the highest TPC from Mentha spatica. In another study, Tatiya et al. (2011) report that $70 \%$ acetone is the best solvent for the recovery of phenolic compounds from Bridelia retusa. Taha et al. (2011) also report that phenolic compounds were best extracted from sunflower meal by conventional extraction method using $80 \%$ acetone as solvent. $70 \%$ acetone was also the best solvent concentration for extracting total phenolic content from Ceratonia siliqua pulp (Benchikh and Louailèche, 2014). Results of the present study are however, contrary to the findings of Settharaksa et al. (2014) who report 
that phenolic componds are best extracted from Syzygium gratum using water. Azman et al. (2013) also report that $100 \%$ ethanol produced the best total phenolic content in Betula alba and Convolvulus arbensis. Polarity of solvents plays significant role in the extraction of phenolic antioxidants. Polyphenol extraction is enhanced by providing more polar medium due to addition of small quantity of water (Fatiha et al., 2012). Even though some chemicals such as sugars, ascorbic acid, sulphur dioxide interfere in FolinCiocalteau method, it remains the best assay for determining total phenolic content from natural products (Azman et al., 2013).

\section{Total Flavonoid Content}

Effect of solvent on the total flavonoid content (TFC) in G. senegalensis leaves is presented in Figure 2. From the figure, it could be seen that extraction solvent significantly $(p<0.05)$ affects extraction of total flavonoid. TFC ranges from $37.22 \pm 5.91 \mathrm{mg} \mathrm{QE} / 1 \mathrm{~g}$ DW to $414.60 \pm 7.60 \mathrm{mg}$ QE/1g DW. 75\% acetone gave the highest TFC (414.60 $\pm 7.60 \mathrm{mg} \mathrm{QE} / 1 \mathrm{~g} \mathrm{DW}$ ) followed by $50 \%$ (364.82 $\pm 38.47 \mathrm{mg} \mathrm{QE} / 1 \mathrm{~g}$ DW) while the least TFC $(37.22 \pm 5.91 \mathrm{mg}$ QE/1g DW) was observed in $75 \%$ chloroform. Our result agrees with the findings of Medini et al. (2014) who report that total flavonoids in Limonium delicatulum flowers were best extracted using $80 \%$ acetone. Boulekbache-Makhlouf et al. (2013) also report that flavonoids from Solanum melongena byproducts are best extracted using 70\% acetone. Ammar et al. (2015) however, report that methanol is the best solvent for extracting total flavonoid from Puntia ficus- indica compared to acetone or ethanol. According to Do et al. (2014), 100\% ethanol gave the highest total flavonoid from Limnophila aromatica, whereas ethyl acetate was the best solvent for extracting total flavonoid from banana peels (Fidrianny et al., 2014). In this study, it can be seen that $75 \%$ solvents concentrations produced higher TFC than water or $50 \%$ solvents concentrations except for chloroform where $50 \%$ produced more TFC than $75 \%$. This shows that the total flavonoid present in $G$. senegalensis are hydrophobic while the less TFC in $75 \%$ chloroform could be explained by the less polarity of chloroform which prevents it from dissolving more polar flavonoids.

\section{2,2'- diphenyl-1- picrylhydrazyl (DPPH) radical scavenging activity}

Results of DPPH radical scavenging activity of $G$. senegalensis as affected by extraction solvent is presented in Figure 3. Results show that all the extracting solvents except $75 \%$ chloroform possess considerably high DPPH radical scavenging activity ranging from $85.40 \%$ to 95 . $82 \%$ while that of $75 \%$ chloroform, which is the least is $2.74 \%$. The highest DPPH scavenging was observed in water followed by $50 \%$ chloroform. It is interesting to note that chloroform that gave least scavenging activity at $75 \%$ displayed higher activity which is significantly $(p<0.05)$ similar to that displayed by water. This may be explained by the fact that amount of water present in $50 \%$ chloroform is sufficient to extract hydrophilic antioxidant while the remaining chloroform extracted other nonpolar antioxidants. It is noteworthy that all the solvents that gave better TPC and TFC showed relatively lower DPPH scavenging property. This may be explained by the fact that it is not only phenolic compounds that are responsible for antioxidant activity, but also other cellular components such as carbohydrates and other chemicals. In fact, any compound that can donate hydrogen radical can enhance scavenging activity (Thoo et al., 2010). DPPH radical scavenging assay is commonly used to evaluate antioxidant property of natural products. The assay depends on the ability of compounds to reduce DPPH radical via hydrogen donating forming a yellowish non radical form of DPPH-H (Hwang and Thi, 2014). Previous studies however, revealed that best DPPH radical scavenging is achieved using aqueous solvents. Bendiabdellah et al. (2012) for example, reported that methanolic extract of Daucus crinitus exhibited the highest DPPH scavenging compared to water extract. Highest DPPH scavenging in both Hongkon and Eksotica 
cultivars of Carica papaya was observed in $50 \%$ methanol (Addai et al., 2013). 70\% ethanol was also the best solvent for quenching DPPH radical in Triticum aestivum bran (Abozaid et al., 2014).

\section{Ferric reducing antioxidant power (FRAP)}

Extraction solvent significantly $(p<0.05)$ affects ferric reducing power of $G$. senegalensis leaves (Figure 4). Results of the present study reveals that $50 \%$ choloroform possess the highest (282.74mg AAE/100g DW) ferric reducing power although its value is not significantly different $(P<$ 0.05 ) from what was observed in $50 \%$ methanol, $75 \%$ methanol and $75 \%$ acetone $(274.67,274.45$ and $259.48 \mathrm{mg} \mathrm{AAE} / 100 \mathrm{~g}$ DW, respectively). $75 \%$ chloroform still showed the least FRAP value $(0.41 \mathrm{mg}$ AAE $/ 100 \mathrm{~g}$ DW). FRAP assay is based on the reduction of $\mathrm{Fe}^{3+}$ to $\mathrm{Fe}^{2+}$ in the presence of tripyridyltriazine (TPTZ) by antioxidant compound following donating of an electron thereby forming an intense blue TPTZ- $-\mathrm{Fe}^{2+}$ complex whose absorbance can be measured at $593 \mathrm{~nm}$. Although $50 \%$ chloroform produced relatively lower TFC (Figure 2), its high ferric reducing activity in this study may be attributed to its considerably high TPC (Figure 1) as well as its ability to dissolve other less polar compounds which could donate electron to the FRAP reagent. Some previous studies also report that chloroform extracts showed good FRAP values. Li et al. (2014) for example report that chloroform extract of Naematoloma sublateritium gave the best FRAP value compared to hexane, butanolic, ethyl acetate and water extracts. Ahmed et al. (2012) also report that chloroform fraction of Melilotus indicus showed highest FRAP value compared to methanolic, hexane, ethyl acetate, butanolic and water extracts at fruiting season. Moreover, chloroform extract of Curcuma zedoaria showed the highest FRAP value (Abbasi et al., 2011). Lu et al. (2013) however, report that chloroform extract of Cymbopogan citratus showed little ferric reducing power compared to gallic acid and ascorbic acid. Chloroform extract also showed least ferric reducing activity compared to acetone, methanol and water extracts in Bauhinia vahlii
(Sowndhararajan and Kang, 2013). Ajaib et al. (2013) report that methanolic extract of Iris aitchisonii showed highest FRAP value compared to chloroform and ethyl acetate extracts.

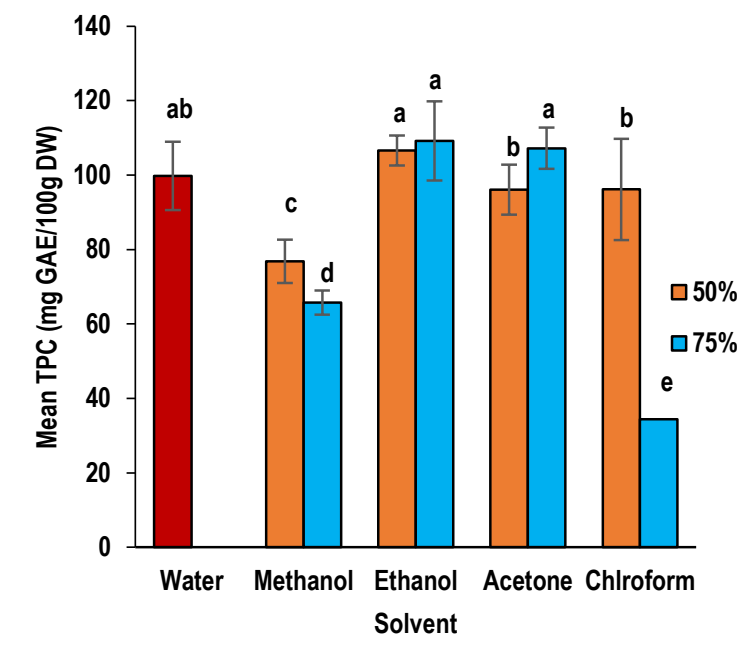

Figure 1: Effect of extraction solvent on total phenolic content (TPC) in Guiera senegalensis leaves. Note: values are means of 6 replicates, error bars represent standard deviation and values with same superscript are not significantly different $(P<0.05)$.

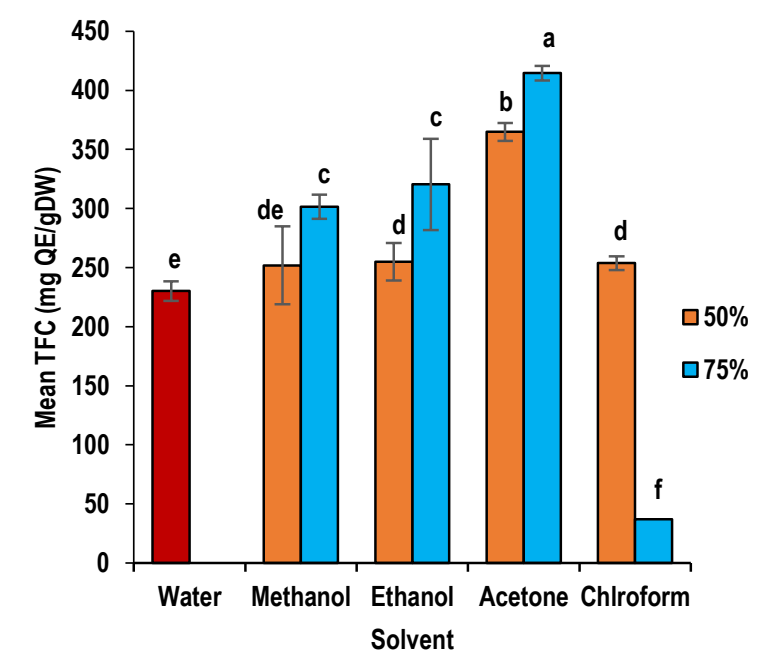

Figure 2: Effect of extraction solvent on total flavonoid content (TFC) in Guiera senegalensis leaves. Note: values are means of 6 replicates, error bars represent standard deviation and values with same superscript are not significantly different $(P<0.05)$. 


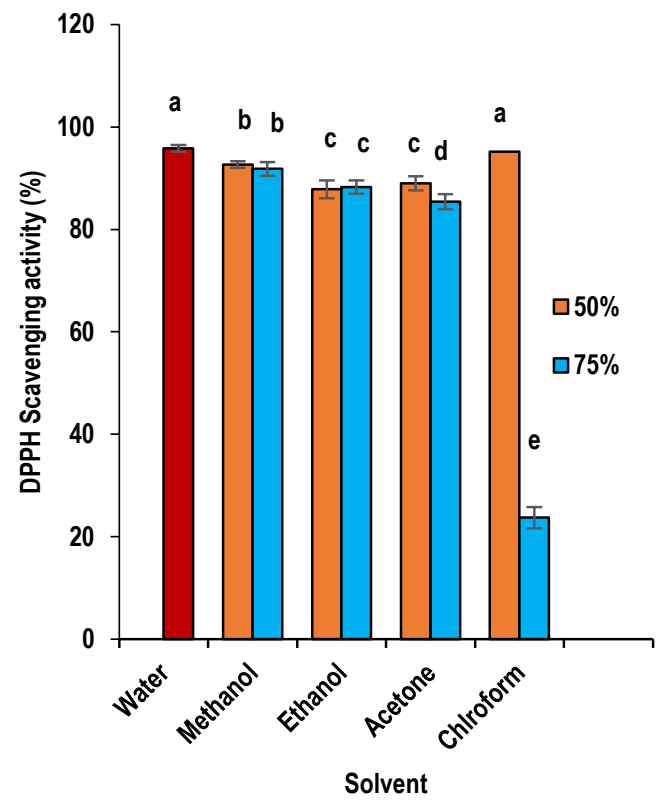

Figure 3: Effect of extraction solvent on DPPH radical scavenging activity in Guiera senegalensis leaves. Note: values are means of 6 replicates, error bars represent standard deviation and values with same superscript are not significantly different $(P<0.05)$.

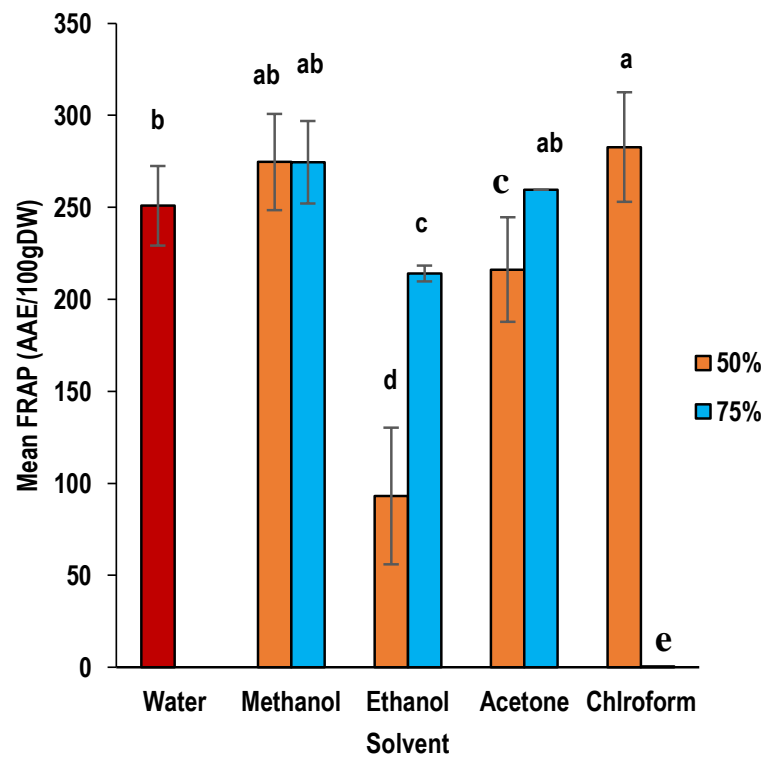

Figure 4: Effect of extraction solvent on ferric reducing antioxidant power (FRAP) in Guiera senegalensis leaves. Note: values are means of 6 replicates, error bars represent standard deviation and values with same superscript are not significantly different $(P<0.05)$.

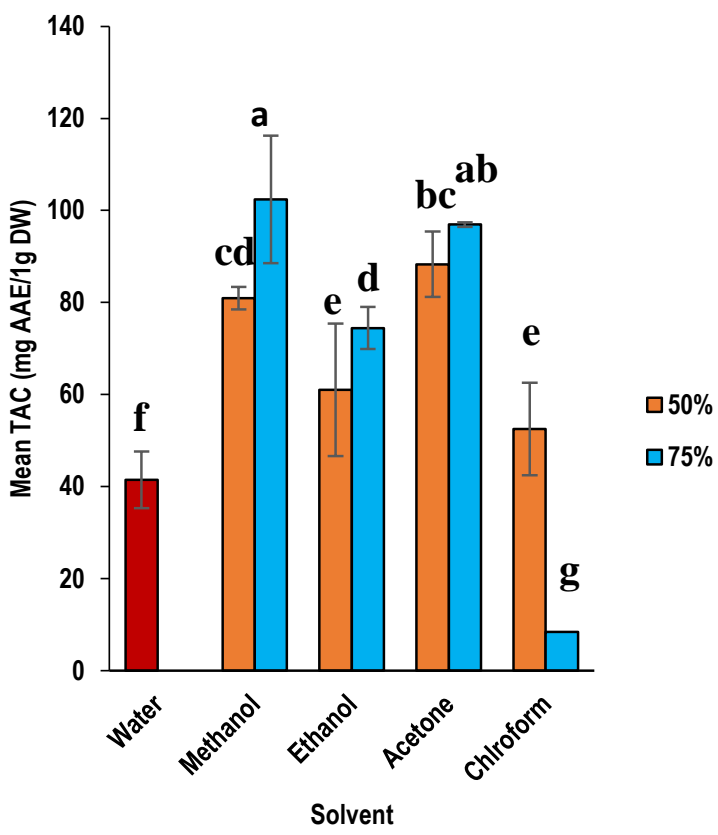

Figure 5: Effect of extraction solvent on total antioxidant capacity (TAC) in Guiera senegalensis leaves. Note: values are means of 6 replicates, error bars represent standard deviation and values with same superscript are not significantly different $(P<$ 0.05).

\section{Total Antioxidant Capacity (TAC)}

Phosphomolybdate assay, a quantitative assay used to determine both water and fat soluble antioxidants (total antioxidant capacity) is based on the reduction of $\mathrm{Mo}(\mathrm{VI})$ to $\mathrm{Mo}(\mathrm{V})$ by antioxidant compounds. This reduction lead to the formation of green phosphate/molybdate complex which can be measured at $695 \mathrm{~nm}$ wavelength (Dutta et al., 2012). In this study, $75 \%$ methanol showed highest activity (102.44mg AAE/1g DW) but not significantly ( $p<$ 0.05 ) different from $75 \%$ acetone $(96.93 \mathrm{mg}$ AAE $/ 1 \mathrm{~g} \mathrm{DW})$. The least activity $(8.42 \mathrm{mg} \mathrm{AAE} / 1 \mathrm{~g}$ DW) was observed in $75 \%$ chloroform (Figure 5). The highest activity observed in aqueous methanol can be ascribed to its ability to dissolve more fat soluble antioxidants in addition to the water soluble ones. Previous studies also revealed that methanolic extracts of plant samples produced significantly higher total 
antioxidant capacity (TAC). Iqbal et al. (2014) for example, report that methanolic extract of Fagonia cretica roots exhibited higher TAC than hexane, chloroform, ethyl acetate butanol and water extracts. Best TAC was also observed in methanolic extract of Ionidium suffruticosum compared to petroleum ether and ethyl acetate extracts (Muthu et al., 2011). Shahwar and Raza (2012) also report that methanol extract of Mimisops elengi showed highest TAC compared to acetone, ethyl acetate and butanol extracts. On the contrary, Jan et al. (2013) report that hexane extract displayed best TAC in Monotheca buxifolia fruits compared to methanol, ethyl acetate, butanol and water extracts. Hexane extract also showed highest TAC compared to butanol, methanol, chloroform, acetone and water extract in Oxalis corniculata (Ahmed et al., 2013). Baig et al. (2011) however, report that butanol extract of Rumex acetosella showed highest TAC compared to chloroform, ethyl acetate, hexane and water extracts.

\section{Correlation Analysis}

Correlation analysis is significant in evaluating relationship between phenolic compounds and antioxidant properties of test samples. In this study, correlation analysis revealed that a highly significant $(p<0.01)$ positive correlations exist between phenolic antioxidant (TPC and TFC) and antioxidant properties (DPPH, FRAP and TAC) as shown in Table 1. The highest correlation $(r=0.845)$ was observed between TFC and TAC followed by TFC and DPPH ( $r=$ $0.733)$. Another significant correlation $(r=0.659)$ was also observed between TFC and FRAP. Based on this high correlations observed between TFC and all the antioxidant assays (DPPH, FRAP and TAC), we suggest that $G$. senegalensis contains more flavonoids than phenolic compounds and are mostly responsible for its antioxidant properties. Addai et al. (2013) also observed significant high correlation between TFC and antioxidant activities (FRAP, DPPH and ABTS) in two cultivars of Carica papaya under the influence of extraction solvent. Jain et al. (2014) however report high correlation between TPC and antioxidant activities (FRAP and $A B T S$ ) in Helicteres isora. The same authors also report that no correlation exist between TPC and DPPH.

Table 1: Correlation between phenolic antioxidants and antioxidant activities as affected by different solvents in $G$. senegalensis $(n=6)^{y}$

\begin{tabular}{ccccc}
\hline$r$ & TPC & TFC & DPPH & FRAP \\
\hline TFC & $0.703^{* *}$ & & \\
DPPH & $0.727^{* *}$ & $0.733^{* *}$ & & \\
FRAP & $0.444^{* *}$ & $0.659^{* *}$ & $0.813^{* *}$ \\
TAC & $0.392^{* *}$ & $0.845^{* *}$ & $0.641^{* *}$ & $0.629^{* *}$ \\
\hline replications & & \\
r correlation coefficient \\
TPC, total phenolic content; TFC, total flavonoid content; DPPH, \\
DPPH radical scavenging activity; FRAP, ferric reducing \\
antioxidant power; TAC, total antioxidant capacity \\
"Significant level at $p<0.01$
\end{tabular}

\section{CONCLUSION}

The present study has indicated that extraction solvents significantly affect extraction of phenolic antioxidants and antioxidant properties of $G$. senegalensis. This study also revealed that all the solvents tested except $75 \%$ chloroform showed good value for one of the assays or another. Based on this it is inferred that $G$. senegalensis possesses different phenolic compounds with varied polarity hence solubility. In general, this study substantiates the potency of $G$. senegalensis leaves as source of natural antioxidants. Further studies using high tech analytical methods such as HPLC is hereby recommended to identify and isolate individual components responsible for the antioxidant properties of this plant.

\section{ACKNOWLEDGEMENTS}

The first author would like to thank the Management of Umaru Musa Yar'adua Univesity, Katsina for the PhD Scholarship award. We are also grateful to the laboratory staff of Plant Systematics and Microbes Laboratory, Department of Biology, Universiti Putra Malaysia for their invaluable support. 


\section{REFERENCES}

Abbasi, M.A, Riazl, T., Azizur-Rehman, T.S., Muhammad, Z.Q. and Khan, K.M. (2011). Antioxidant activity and radical scavenging effects of various fractions from Curcuma zedoaria. Asian Journal of Pharmaceutical and Biological research, 1(4): 525-533.

Abozed, S.S., El-kalyoubi, M., Abdelrashid, A., and Salama, M.F. (2014). Total phenolic contents and antioxidant activities of various solvent extracts from whole wheat and bran. Annals of Agricultural Sciences, 59(1): 63-67.

Abubakr M., Sirag N, Osman I, Abakar S. and Aboul Enien A.M. (2013). Anticancer and antioxidant activities of Guiera senegalensis. Sudan Journal of Medical Sciences 8(3): 135140.

Addai, Z.R., Abdullah, A. and Mutalib, S.A. (2013). Effect of extraction solvents on the phenolic content and antioxidant properties of two papaya cultivars. Journal of Medicinal Plants Research, 7(47): 3354-3359.

Ahmed, D., Baig, H. and Zara, S. (2012). Seasonal variation of phenolics, flavonoids, antioxidant and lipid peroxidation inhibitory activity of methanolic extract of Melilotus indicus and its sub-fractions in different solvents. International Journal of Phytomedicine 4: 326-332.

Ahmed, D. Saman, Z. and Baig, H. (2013). In vitro analysis of antioxidant activities of Oxalis corniculata Linn. fractions in various solvents. African Journal of Traditional Complementary and Alternative Medicine 10(1): 158-165.

Ajaib, M., Khan, Z., Abbasi, M. A. and Siddiqui, S.Z. (2013). Iris aitchisonii (Bakar) Boiss: A potential source of natural antioxidants. Biologia (Pakistan) 59: 345-348.

Ammar, I., Ennouri, M. and Attia, H. (2015). Phenolic content and antioxidant activity of cactus (Opuntia ficus-indica L.) flowers are modified according to the extraction method. Industrial Crops and Products 64: 97-104.

Ancolio, C., Azas, N., Mahiou, V., Ollivier, E., Di Giorgio, C., Keita, A., Timon-David, P. and Balansard, G. (2002). Antimalarial activity of extracts and alkaloids isolated from six plants used in traditional medicine in Mali and Sao Tome. Phytotherapy Research 16 : 646-649.

Aniagu S.O., Binda L.G., Nwinyi F.C., Orisadipe A., Amos S., Wambebe C. and Gamaniel, K. (2005). Anti-diarrhoeal and ulcer-protective effects of the aqueous root extract of Guiera senegalensis in rodents. Journal of Ethnopharmacology 97: 549-554.

Azman A. Nurul, M. Husni Shafik, Almajano P. and Maria, G.G.M. (2013). Solvent effect on antioxidant activity and total phenolic content of Betula alba and Convolvulus arvensis. International Journal of Biological, Veterinary, Agricultural and Food Engineering, 7(5): 152157.

Baig, H., Ahmed, D. and Zara, S. (2011). In vitro evaluation of antioxidant properties of different solvent extracts of Rumex acetosella Leaves. Oriental Journal Of Chemistry, 27(4): 1509-1516.

Benchikh, Y. and Louaileche, H. (2014). Effect of extraction conditions on the recovery of phenolic compounds and in vitro antioxidant activity of carob (Ceratonia siliqua L.) pulp. Acta Botanica Gallica, 161(2): 175- 181.

Bendiabdellah, A., El, M., Dib, A., Meliani, N., Allali, H., Tabti, B. and Meliani, N. (2012). Preliminary phytochemical screening andantioxidant activities of solvent extracts from Daucus crinitus Desf. from Algeria. Journal of Applied Pharmaceutical Science, 2(7): 92-95.

Benoit, F., Valentin, A., Pelissier, Y., Diafouka, F., Marion, C., Kone-Bamba, D., Kone, M., Mallie, M., Yapo, A. and Bastide, J.M., (1996). In vitro antimalarial malarial activity of vegetal extracts used in West African traditional medicine. American Journal of Tropical Medicine and Hygiene, 54: 67-71.

Boeing, J.S., Barizão, E.O., E Silva, B.C., Montanher, P.F., de Cinque Almeida, V. and Visentainer, J.V. (2014). Evaluation of solvent effect on the extraction of phenolic compounds and antioxidant capacities from the berries: application of principal component analysis. Chemistry Central Journal, 8(1): 48.

Boulekbache-Makhlouf, L., Medouni, L., MedouniAdrar, S., Arkoub, L. and Madani, K. (2013). 


\section{Nigerian Journal of Basic and Applied Science (December, 2016), 24(2): 116-125}

Effect of solvents extraction on phenolic content and antioxidant activity of the byproduct of eggplant. Industrial Crops and Products, 49: 668-674.

Brewer, M.S. (2011). Natural antioxidants: sources, compounds, mechanisms of action and potential applications. Comprehensive Reviews in Food Science and Food Safety, 10(4): 221-247.

Do, Q.D., Angkawijaya, A.E., Tran-Nguyen, P.L., Huynh, L.H., Soetaredjo, F.E., Ismadji, S. and Ju, Y.H. (2014). Effect of extraction solvent on total phenol content, total flavonoid content, and antioxidant activity of Limnophila aromatica. Journal of Food and Drug Analysis, 22(3): 296-302.

Dutta, A.K., Gope, P.S., Makhnoon, S., Rahman, S., Siddiquee, M.A. and Kabir, Y. (2012). Effect of solvent extraction on phenolic content, antioxidant and a- Amylase inhibition activities of Swertia. International Journal of Drug Development and Research, 4(4): 317325.

Fatiha, B., Khodir, M., Farid, D., Tiziri, R., Karima, B., Sonia, O. and Mohamed, C. (2012). Optimisation of solvent extraction of antioxidants (Phenolic Compounds) from Algerian mint (Mentha spicata L.). Pharmacognosy Communications, 2(4): 72 86.

Fiot, J., Sanon, S., Azas, N., Mahiou, V., Jansen, O., Angenot, L. and Ollivier, E. (2006). Phytochemical and pharmacological study of roots and leaves of Guiera senegalensis J.F. Gmel (Combretaceae). Journal of Ethnopharmacology, 106(2): 173-8.

Hwang, E.S. and Thi, N.D. (2014). Effects of extraction and processing methods on antioxidant compound contents and radical scavenging activities of Laver (Porphyra tenera). Preventive Nutrition and Food Science, 19(1): 40-8.

Fidrianny, I.K. and Rizki, R.M.I. (2014). In vitro antioxidant activities from various extracts of banana peels using ABTS, DPPH assays and correlation with phenolic, flavonoid and carotenoid content. International Journal of Pharmacy and Pharmaceutical Sciences, 6(8): 299-303.
Iqbal, P., Ahmed, D. and Asghar, M.N. (2014). A comparative in vitro antioxidant potential profile of extracts from different parts of Fagonia cretica. Asian Pacific Journal of Tropical Medicine, 7(1): 473-480.

Jain, A., Sinha, P. and Neetin. S.D. (2014). Estimation of flavonoid, phenol content and antioxidant potential of indian screw tree (Helicteres isora L.). International Journal of Pharmaceutical Sciences and Research, 5(4): 1320-1330.

Jan, S., Khan, M.R., Rashid, U. and Bokhari, J. (2013). Assessment of antioxidant potential, total phenolics and flavonoids of different solvent fractions of Monotheca buxifolia fruit. Osong Public Health and Research Perspectives, 4(5): 246-54.

Lu, Y., Shipton, F.N., Khoo, T.J. and Wiart, C. (2014). Antioxidant activity and determination of citronellal from crude extracts of Cymbopogon citratus by 3 different methods. Pharmacology and Pharmacy, 5: 395-400.

Kaur S. and Mondal P. (2014) Study of total phenolic and flavonoid content, antioxidant activity and antimicrobial properties of medicinal plants. Journal of Microbiology and Experimentation 1(1): 00005.

Koltover V.K. (2010). Antioxidant biomedicine: from free radical chemistry to systems biology mechanisms. Russian Chemical Bulletin, 59(1): $37-42$.

Kudi, A.C., Umoh, J.U., Eduvie, L.O. and Gefu, J. (1999). Screening of some Nigerian medicinal plants for antibacterial activity. Journal of Ethnopharmacology, 67: 225228.

Lamien C.E., Meda, J. Mans, M. Romito, O.G. Nacoulma and Viljoen, G.J. (2005). Inhibition of fowlpox virus by an aqueous acetone extract from galls of Guiera senegalensis J.F. Gmel (Combretaceae) Journal of Ethnopharmacology, 96: 249253.

Mariod, A., Matthäus, B. and Hussein, I.H. (2006). Antioxidant activities of extracts from Combretum hartmannianum and Guiera senegalensis on the oxidative stability of sunflower oil. Emir Journal of Agricultural Science, 18(2): 20-28. 
Medini, F., Fellah, H., Ksouri, R. and Abdelly, C. (2014). Total phenolic, flavonoid and tannin contents and antioxidant and antimicrobial activities of organic extracts of shoots of the plant Limonium delicatulum. Journal of Taibah University for Science, 8(3): 216-224.

Mohammed, C.B., Chahid, B., Fatima, B., FatimaZohra, S., Meriem, B. and Farid, C. (2014). Antioxidant activity, phenolic and flavonoid content in leaves, flowers, stems and seeds of mallow (Malva sylvestris L.) from North Western of Algeria. African Journal of Biotechnology, 13(3): 486-491.

Muthu, A.K., Kumar, D.S. and Manavalan, R. (2011). In vitro antioxidant potential of various extracts from whole plant of Ionidium suffruticosum (Ging). International Conference on Biotechnology and Pharmaceutical Sciences, 4(6): 369-371

Settharaksa, S.F. Madaka, L., Sueree, S., Kittiwisut, A., Sakunpak, C. and Moton, L.C. (2014). Effect of solvent types on phenolic, flavonoid contents and antioxidant activities of Syzygium gratum (Wight) S.N. International Journal of Pharmacy and Pharmaceutical Sciences, 6(2): 2-4.

Shahwar, D. and Raza, M.A. (2012). Antioxidant potential of phenolic extracts of Mimusops elengi. Asian Pacific Journal of Tropical Biomedicine, 2(7): 547-50.

Shalaby, E.A. and Shanab, S.M.M. (2013). Antioxidant compounds, assays of determination and mode of action. African Journal of Pharmacy and Pharmacology, 7(10): 528-539.

Sombie, P.A.E.D., Hilou, A., Mounier, C., Coulibaly, A.Y., Kiendrebeogo, M. J.F.M. and O.G.N. (2011). Antioxidant and anti-inflammaory activities from galls of Gueira senegalensis
J.F. Gmel (Combretaceae). Research Journal of Medicinal Plants, 5(4): 448-461.

Sowndhararajan, K. and Kang, S.C. (2013). Free radical scavenging activity from different extracts of leaves of Bauhinia vahlii Wight \& Arn. Saudi Journal of Biological Sciences, 20(4): 319-325.

Tatiya, A.U., Tapadiya, G.G., Kotecha, S. and Surana, S.J. (2011). Effect of solvents on total phenolics, antioxidant and antimicrobial properties of Bridelia retusa Spreng. stem bark. Indian Journal of Natural Products and Resources, 2: 442-447.

Taha F.S., Mohamed, G.F., Mohamed S.H., Mohamed S.S. and Kamil M.M. (2011). Optimizing of the extraction of total phenolic compounds from sunflower meal and evaluation of the bioactivities of chosen extracts. American Journal. of Food Technology, 6(12): 1002-1020.

Tan, E.S., Abdullah, A. and Maskat, M.Y. (2013). Effect of drying methods on total antioxidant capacity of bitter gourd (Momordica charantia) fruit. AIP Conference Proceedings, 1571: 710-716.

Thaipong K., Boonprakob U., Crosby K., CisnerosZevallos L. and Byrne, D.H. (2006). Comparison of ABTS, DPPH, FRAP, and ORAC assays for estimating antioxidant activity from guava fruit extracts. Journal of Food Composition Analysis, 19: 669-675.

Thoo, Y.Y., Ho, S.K., Liang, J.Y., Ho, C.W. and Tan, C.P. (2010). Effects of binary solvent extraction system, extraction time and extraction temperature on phenolic antioxidants and antioxidant capacity from mengkudu (Morinda citrifolia). Food Chemistry, 120(1): 290-295. 